\title{
Sterculia apetala
}

Sterculia apetala (Jacq.) H. Karsten. (1869).

Publicado en: Florae Columbiae terraumque adjacentium specimina

- STERCULIACEAE selecta in peregrinatione duodecim annorum observata delineavit et descripsit 2: 35, pl. 118. 1869.

Nombres comunes en México. Arbol del Bellote, Bellota (Tab.); Castaña, Castaño, Bellota (Chis.); Pepetaca, Petaca (Oax.); Tepetaca (centro de Ver., norte de Oax.).

Sinonimia. Chichaca acerifolia Presl. ; Helicteres apetala Jacq. ; Sterculia acerifolia Hemsl. ; Sterculia apetala var. elata (Ducke) E.L. Taylor ; Sterculia carthaginensis Cav. ; Sterculia elata Ducke ; Sterculia punctata DC.

\section{DESCRIPCION}

Forma. Arbol exótico, grande y hermoso, caducifolio, de 30 a $40 \mathrm{~m}$ de altura, con un diámetro a la altura del pecho de hasta $2 \mathrm{~m}$.

Copa / Hojas. Copa redondeada y densa (cerrada). Hojas en espiral, aglomeradas en las puntas de las ramas, palmado-lobadas, con tres lóbulos grandes y dos inferiores más pequeños; de 15 a $50 \mathrm{~cm}$ de largo incluyendo el pecíolo; margen entero.

Tronco / Ramas. Tronco recto y cilíndrico, a veces con contrafuertes muy grandes y aplanados, originándose muy arriba del tronco. Ramas horizontales.

Corteza. Externa lisa o con pequeñas escamas, gris pardusca, con grandes lenticelas redondas. Interna de color muy claro cambiando a crema morena con abundantes expansiones de parénquima, granulosa, con exudado pegajoso y transparente. Grosor: $15 \mathrm{a}$ $25 \mathrm{~mm}$.

Flor(es). Flores en panículas amplias axilares de hasta $25 \mathrm{~cm}$ de largo, densamente estrellado-pubescentes; flores zigomórfas, de 2.5 a $3.5 \mathrm{~cm}$ de diámetro. Flores masculinas con perianto verde, con pelos guindas en la superficie externa y bandas rojas oscuras y guindas en la superficie interna, ampliamente campanulado con 5 a 6 lóbulos ovados, agudos, valvados, densamente estrellado-pubescentes en la superficie externa, y con una nervadura muy prominente en la superficie interna; estambres numerosos, unidos en una columna. Flores femeninas parecidas a las masculinas pero con estambres reducidos a una sola serie que rodea la base del ovario y densamente tomentosos.

Fruto(s). Compuestos de hasta de 5 folículos péndulos en pedúnculos de hasta $30 \mathrm{~cm}$ de largo; folículos sésiles recorvados, de 6 por 3 a 12 por $6 \mathrm{~cm}$, verde amarillentos a parduscos, con abundantes pelos en el exterior, abriéndose por la superficie ventral; el interior con abundantes pelos erectos y muy finos que se clavan fácilmente en la piel.

Semilla(s). Semillas grandes, elipsoides, negras y brillantes, de 2.5 por $1.5 \mathrm{~cm}$. Contienen grasa.
Raíz. Desarrollan raíces tubulares prominentes y angostas, más altas que anchas.

Sexualidad. Dioica, polígama.

DISTRIBUCION

Se encuentra en la vertiente del Golfo, desde el sur de la Sierra de Naolinco en el centro de Veracruz y norte de Oaxaca, hasta el norte de Tabasco y Chiapas y en la vertiente del Pacífico en Chiapas. Altitud: 0 a 300 m.

Estados. CHIS. OAX. SIN. TAB. VER.

\section{ORIGEN / EXTENSION}

Originario de América Central. Se extiende desde el sur de México y Centroamérica hasta Perú y Brasil. Se ha naturalizado en Jamaica y Trinidad y se ha sembrado en el sur de Florida (Estados Unidos), Cuba, La Española, Puerto Rico e Islas Vírgenes.

ESTATUS

Cultivada. Silvestre.

HABITAT

Crece a orilla de carreteras, en potreros, lomeríos, terrenos planos, pendientes pronunciadas y relictos de selva. Donde alcanza su máximo desarrollo es a lo largo de los ríos. Prospera tanto en suelos someros derivados de material calizo, como en suelos lateríticos profundos derivados de aluviones antiguos;

alcanzando su máximo desarrollo en este tipo de suelos Suelos: arcilloso profundo, negro con abundantes rocas, arenoso, rojo-arcilloso con basalto.

IMPORTANCIA ECOLOGICA

Especie Primaria.

\section{VEGETACION / ZONA ECOLOGICA}

Tipos de Vegetación.

- Bosque de galería.

- Bosque tropical caducifolio.

- Bosque tropical perennifolio.

- Bosque tropical subcaducifolio.

- Bosque tropical subperennifolio.

- Pastizal.

- Palmar. 


\section{Sterculia apetala}

Vegetación asociada. Lonchocarpus guatemalensis, Enterolobium cyclocarpum, Bursera simaruba, Sabal mexicana, Brosimum sp., Terminalia amazonia, Dialium guianense, Didimopanax morototoni, Zanthoxylum kellermanii, Croton glabelus, Inga spuria, Conostegia hiertella.

Zona(s) ecológica(s). Trópico húmedo. Trópico subhúmedo.

\section{FENOLOGIA}

Follaje. Caducifolio. Pierde el follaje durante una época corta del año.

Floración. Florece de diciembre a julio.

Fructificación. No disponible.

Polinización. No disponible.

\section{ASPECTOS FISIOLOGICOS}

Adaptación. No disponible.

Competencia. No disponible.

Crecimiento. Especie de rápido crecimiento y de buena forma.

Descomposición. No disponible.

Establecimiento. No disponible.

Interferencia. No disponible.

Producción de hojas, frutos, madera y/o semillas.

No disponible.

Regeneración. No disponible.

\section{SEMILLA}

Almacenamiento / Conservación. No disponible. Dispersión. No disponible.

Germinación. Necesita de 0 a 4 semanas de incubación para germinar. El tiempo promedio que tarda en germinar es de 12 días.

Porcentaje de germinación. No disponible. Número de semillas por kilogramo: No disponible.

Recolección / Extracción. No disponible.

Tratamiento pregerminativo. No disponible.

Viabilidad / Latencia / Longevidad. Presenta latencia física. Cubierta impermeable.

\section{EXPERIENCIAS CON LA PLANTA}

Plantación Comercial / Productiva / Experimental. No disponible.

Reforestación / Restauración. Especie con potencial para reforestación productiva en zonas degradadas de selva.

Sistema agroforestal. Podría aplicarse en sistemas de cultivos en estratos múltiples, callejones forrajeros, cortinas rompevientos y barbechos mejorados.

CULTIVO

Aspectos del cultivo. No disponible.

PROPAGACION

Reproducción asexual. 1. Cortes de tallo.

Reproducción sexual. 1. Siembra directa. 2. Semilla (plántulas).

\section{EFECTO RESTAURADOR / SERVICIO AL AMBIENTE}

Efecto(s) restaurador(es). 1. Conservación de suelo / Control de la erosión.

Servicio(s). 1. Cerca viva en los agrohábitats. 2. Sombra / Refugio. 3. Ornamental. En Puerto Rico el valor principal de esta especie es sombra y ornato.

4. Barrera rompevientos.

TOLERANCIAS

Demandante de. No disponible.

Resistente a. 1. Fuego. 2. Daño por termitas.

Tolerante a. 1. Suelos con mal drenaje.

DESVENTAJAS

Intolerante a. No disponible.

Sensible / Susceptible a. 1. Daño por hongos e insectos (madera).

USOS

Comestible (semilla, bebidas) [semilla]. Semillas comestibles: tostadas tienen sabor a cacahuate, molidas se usan para preparar una bebida refrescante. Tienen un alto contenido de almidón y grasas. Su consumo puede originar diarrea si se toma agua después de ingeridas. Las semillas están cubiertas con pelos tiesos semejantes a agujas que penetran e irritan la piel.

Construcción [madera]. Construcción rural (interiores).

Forrajero [semilla]. Forraje para ganado porcino. Industrializable [toda la planta] Pulpa para papel. Maderable [madera]. Mobiliario y ebanistería, cajas y embalajes, fabricación de canoas.

Melífera [flor]. Apicultura.

Saborizante [semilla]. Las semillas molidas se usan para saborizar el chocolate. 


\section{Sterculia apetala}

\section{COMENTARIOS}

El nombre genérico deriva del latín "Stercus" que significa excremento, debido al olor característico de hojas y flores. Es el árbol nacional de la República de Panamá y se considera que éste originó el nombre del país.

\section{BIBLIOGRAFIA}

Díaz Gómez, Victor y Juana Huerta Crespo. 1986.

Elbert L., Little Jr., F.H. Wadsworth y J. Marrero. 1967. Martínez, Maximino. 1979.

Niembro Rocas, Aníbal. 1986.

Pennington, T.D., y J. Sarukhán. 1968.

Peter G. von Carlowitz, G.V. Wolf and E.M.

Kemperman. 1991.

Rzedowski, Jerzy y Miguel Equihua. 1987.

Saldías, Mario, Roberto Quebedo, Blas García, Anna Lawrence, James Johnson. 1994.

Waterman, P.G. 1994. 